\title{
EFFICACY OF MICRONIZED CALCIUM CARBONATE AS COADJUVANT IN EXTRACTION PROCESS
}

\author{
Marinela Muço ${ }^{1}$ \\ Anila Kopali
}

DOI: https://doi.org/10.31410/ERAZ.2019.347

\begin{abstract}
The use of appropriate processing aids at the correct rates tends to improve oil extraction efficiency in a cost-effective way without adversely affecting the oil quality. The aim of this research was to evaluate the effect of calcium carbonate added at the beginning of the malaxation phase, on both the extraction yield and the quality. The assays were performed with olive oil obtained from Kalinjoti olives at different ripening index. The use as a technological coadjuvant of calcium carbonate, E170 food additive, caused an increase of olive oil extraction yield. Moreover, an increase of pungent perception was observed in some cases when we added calcium carbonate to more ripened olives. Also, micronized carbonate allows a low mixing temperature to be used in extraction yields, resulting in higher quality olive oil. Concerning analytical determinations of oils (acidity, pH, peroxide values, ultraviolet spectrophotometric analysis $K_{232}$ and $K_{270}$,), no significant differences were found when comparing oils obtained with or without carbonate and all of them could be classified as "extra virgin olive oil" according to European norms.
\end{abstract}

Keywords: Virgin olive oil, coadjuvant, calcium carbonate, extraction yield, oil quality.

\section{INTRODUCTION}

$\mathrm{O}$ live oil is a very important product due to its nutritional value, sensory and antioxidant properties. Olive oil has been claimed to be a healthy food whose consumption is associated, for example, to a low mortality by cardiovascular disease [1]. The story of the origin of olive oil in Albania has no difference from its spreading path in the Mediterranean. Albania is a Mediterranean country where it is thought the olive tree has originated. The industrial process includes physical operations [2]. The process begins by washing and leaf removal, Milling or crushing, mixing of the olive paste (malaxation), Oil extraction from the paste by pressing, centrifugal decanters, selective filtration, or through combinations of the different methods. Paste malaxation has been extensively studied because of its influence on oil quality [3] - [5]; temperature and mixing time are the main factors. Among the different types of olive oils that may be produced, virgin olive oil is the most valuable one, as the extraction process preserves its beneficial features. Not all the oil present in the olives is released: some remains inside the unsheltered cells; some are left in the colloidal system of the olive paste (microgels) and some are bound in an emulsion with the vegetable water. The difficulty of freeing this "bound" oil lies mainly in the fact that the droplets of dispersed or emulsified oil are surrounded by a lipoprotein membrane (phospholipids and proteins) that keeps them in that state [6], [7]. To improve coalescence, the paste temperature of the olive paste can be increased, thus reducing viscosity, although oil quality may be reduced as a consequence of too high temperatures [3], [5]. How easy or difficult the olive oil extraction is, has been linked to olive variety and seasonal conditions such as the level of irrigation, time of

Faculty of Technical Science, Department of Chemistry, University of Vlora, Vlora, Albania

Faculty of Biotechnology and Food, Department of Agrifood Technology, Agricultural University of Tirana, Tirana, Albania 
harvesting, type and amount of fertilizer used, the amount of olives per tree or a high incidence of fruits affected by pests (for example, due to Bractocera oleae) or physiological diseases (for example, due to chilling injuries). However, the consistency of the cellulose wall of the olive mesocarp cells and consequently the pectin content, as well as a high level of humidity, seem to be the basis of the emulsions formed, making more difficult the olive oil to be separated [8].

To break down such emulsions, some technological coadjuvants have been successfully developed, e.g. cellular walls degrading enzymes [9] and micronized talc (hydrated magnesium silicate) [10].

Pulverised calcium carbonate, traditionally used as a flocculation coadjuvant (coalescence), acts as supporting material and adsorbent medium facilitating flocs agglomeration. It has crystalline structure (calcite) and negative electric charge and shows no chemical reaction with olive droplets (hydrophobic colloids) [11] - [15]. On the other hand, given the high density of calcium carbonate, $2.72 \mathrm{~g} / \mathrm{cm} 3$, near three times that of olive oil, it is easily eliminated, along with olive pomace, by centrifugation. The novelty of this work relies on the use of calcium carbonate as a physical-acting technological coadjuvant for virgin olive oil extraction. Calcium carbonate is authorized by European Union regulations (Directive 2001/30/CE) and used worldwide as a human food additive (E170). The influence of calcium carbonate in both the extraction yield and the sensorial characteristic of olive oil are presented in this work.

\section{RESULTS AND DISCUSSION}

Olives (Olea europaea L.), "Kalinjoti" varieties, were collected in the northeast and southeast of Vlora city. These olives were collected directly from the tree in harvesting time of the 2018 season. Olive samples were placed in plastic crates and were used for extraction experiments within $24 \mathrm{~h}$ of picking. The olive oil extraction process was carried out according to the pilot system at $25-27^{\circ} \mathrm{C}$ in Center of Agricultural Technology Transfer (CATT) Vlora, Albania.

The productive process of extra virgin olive oil involves: olive crushing, aimed to tear the flesh cells and let the oil run out; olive paste malaxation to enable the merging of oil droplets into larger drops, until they form "pockets" that can be separated into a continuous liquid phase; olive oil separation from the other phases by pressure.

The titratable acidity, the peroxide index, the determination of UV spectrophotometric indices $\left(\mathrm{K}_{232}, \mathrm{~K}_{270}\right)$ were determined from the extracted oils according to the European Union standard methods [16], [17].

Free acidity, given as \% of oleic acid, was determined by titration of a solution of oil dissolved in ethanol-ether (1:1) with ethanolic potash.

Peroxide index, expressed in milliequivalents of active oxygen per kilogram of oil (mEq O2/ $\mathrm{kg}$ ), was determined as follows: a mixture of oil and chloroform acetic acid was left to react with a solution of potassium iodide in darkness; the free iodine was then titrated with a sodium thiosulfate solution.

The UV absorbances were measured at two wavelengths (232 and $270 \mathrm{~nm}$ ), using a 1\% solution of oil in spectrophotometric grade cyclohexane and a path length of $1 \mathrm{~cm}$. Several experiment 
designs have been performed to study the efficacy of calcium carbonate as a technological coadjuvant and the influence of the main operational variables on the virgin olive oil extraction process [18].

Results are summarized in Table 1. The results also show that the calcium carbonate gives a lower acidity, lower peroxide values and lower UV extinction coefficients $\left(\mathrm{K}_{270}\right.$ and $\left.\mathrm{K}_{232}\right)$ than without calcium carbonate. Kalinjoti had lower acidity $(0.36,0.35)$; lower peroxide value (4.8 and 4.5): lower UV extinction coefficients $\left(\mathrm{K}_{270}\right.$ and $\left.\mathrm{K}_{232}\right)(0.11$ and 1.63$)$ with calcium carbonate addition.

Table 1: Values of the parameters established to measure the level of quality of the virgin olive oil obtained

\begin{tabular}{|c|c|c|c|c|c|c|c|}
\hline \multirow{2}{*}{ Variety } & \multirow{2}{*}{$\begin{array}{c}\text { Carbonate } \\
\text { added }\end{array}$} & $\begin{array}{c}\text { Acidity } \\
\mathbf{( \% )}\end{array}$ & $\mathbf{p H}$ & $\begin{array}{c}\text { Peroxides, } \\
\mathbf{m E q} \mathbf{~ O 2 / k g}\end{array}$ & $\mathbf{K}_{\mathbf{2 3 2}}$ & $\mathbf{K}_{\mathbf{2 7 0}}$ & $\Delta \mathrm{K}$ \\
\hline \multirow{3}{*}{ Kalinjoti } & $0 \%($ Control) & 0.44 & 4.92 & 4.9 & 1.69 & 0.14 & -0.003 \\
\cline { 2 - 8 } & $1 \%$ & 0.36 & 5.1 & 4.8 & 1.65 & 0.11 & -0.003 \\
\cline { 2 - 8 } & $2 \%$ & 0.35 & 5.1 & 4.5 & 1.63 & 0.11 & -0.001 \\
\hline
\end{tabular}

The lower values of these quality parameters indicate that calcium carbonate gives better oil quality than without calcium carbonate used in this study. The quality of the oil was better for Kalinjoti cultivar. It is important to note that all the oil samples fulfill the quality requirements set for highest olive oil quality class: Extra Virgin Olive Oil. The olive oil quality ranking is set by the European Commission in the Regulation of (CE) No1989/2003.

The graphical presentations of these quality parameters are in the following figures $1-5$.

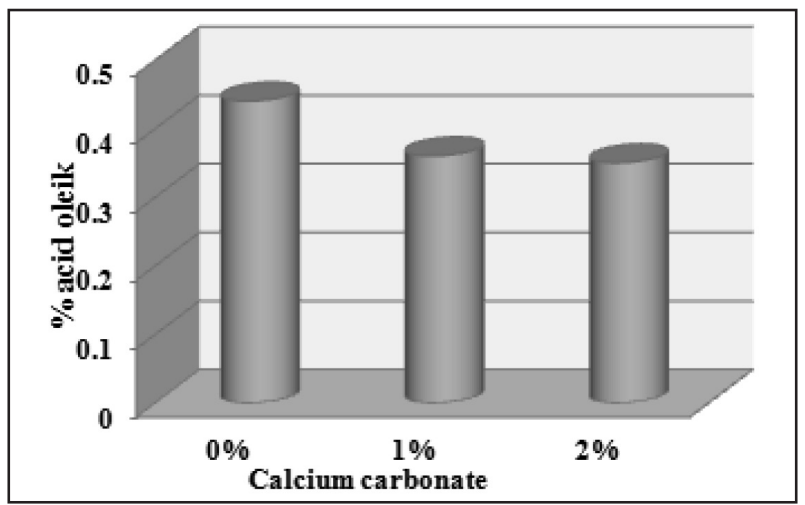

Figure 1. Degree of Acidity for Kalinjoti olive oil

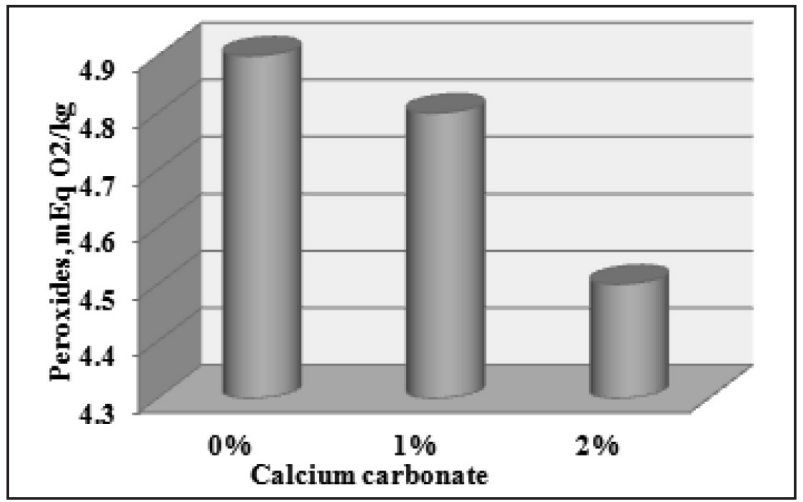

Figure 2. Peroxide value for Kalinjoti olive oil 


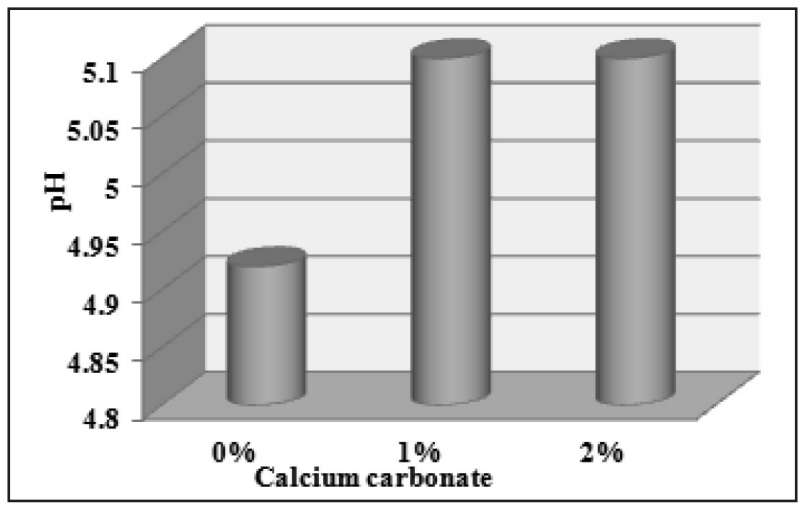

Figure 3. The $\mathrm{pH}$ values for Kalinjoti olive oil

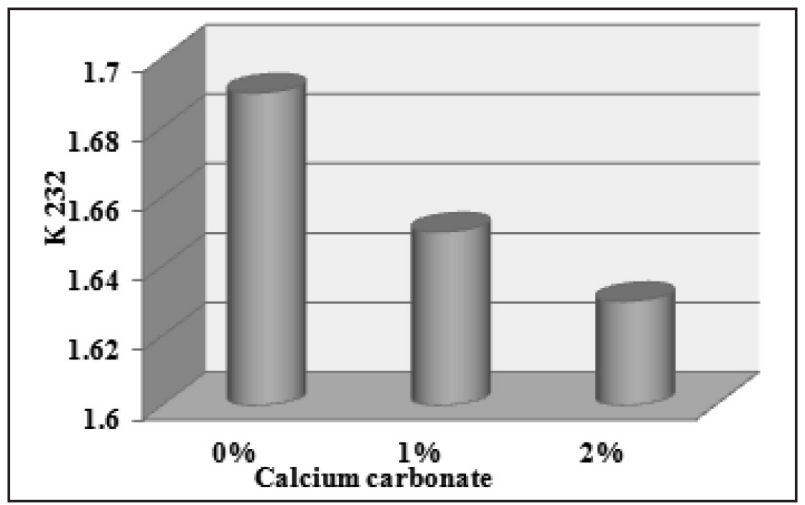

Figure 4. Extinction Coefficient $\mathrm{K}_{232}$

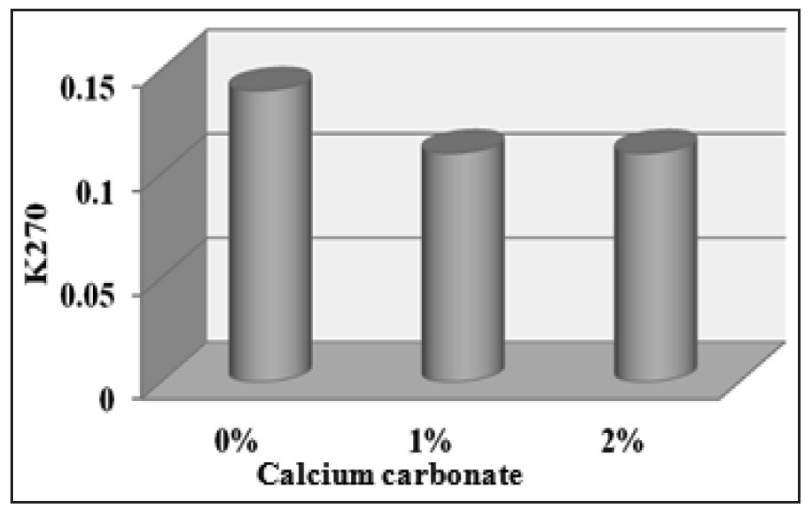

Figure 5. Extinction Coefficient $\mathrm{K}_{270}$

The use of calcium carbonate in extraction process is shown in table 2 and illustrated in figure 6 . The calcium carbonate addition improves the oil yield in two cases. The calcium carbonate addition increased the oil yield for the Kalinjoti cultivar (19.9 $\mathrm{kg}$ oil $/ 100 \mathrm{~kg}$ olives with $1 \%$ calcium carbonate addition and $21.05 \mathrm{~kg}$ oil $/ 100 \mathrm{~kg}$ olives with $2 \%$ calcium carbonate addition). Cultivar Kalinjoti that dominates on the Albanian orchards confirmed as a cultivar of interest for the production of olive oil.

Table 2: Oil extraction yield ( $\mathrm{kg}$ oil /100 kg olives).

\begin{tabular}{|c|c|}
\hline Carbonate added & Kalinjoti Cultivar \\
\hline $0 \%($ Control $)$ & 19.5 \\
\hline $1 \%$ & 19.9 \\
\hline $2 \%$ & 21.05 \\
\hline
\end{tabular}




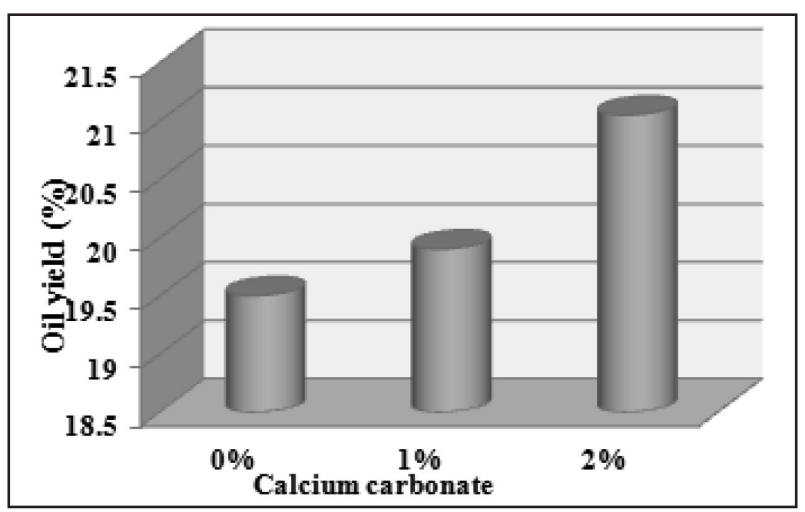

Figure 6. Oil yield (\%) for Kalinjoti cultivar

\section{CONCLUSION}

The purpose of this study was to evaluate the effect of calcium carbonate on the extraction yield and quality of extra virgin olive oils from Albanian autochthonous "Kalinjoti" olives.

As a result of the work, it can be concluded that micronized calcium carbonate is an appropriate technological coadjuvant in the production of virgin olive oil. Moreover, due to its high specific area, carbonate use contributes in obtaining clean oils, with a low level of moisture and fine particles. According to these results, the recommended carbonate dosage is in the range $1-2 \%$ by weight referred to the weight of olive fruits, depending on the fruit variety, the moisture content and the maturity index of olive fruits. The results showed that the calcium carbonate improved the oil yield. On the other hand, the calcium carbonate addition provides higher quality oils.

The acidity, peroxide, UV extinction values were better with calcium carbonate. The quality of the olive oil can be classified as Extra Virgin Olive Oil according to the EU classification system for the olive oils. This indicates that the calcium carbonate offers benefits in olive oil manufacturing.

\section{REFERENCES}

[1] Covas, M.I., (2007) Olive oil and the cardiovascular system, Pharmacological Research 55, pp. 175-186.

[2] Commission of the European Communities, (2001) Commission directive 2001/30/EC of 2 May 2001 amending directive 96/77/EC laying down specific purity criteria on food additives other than colours and sweeteners, Official Journal of the European Communities L 146, pp. 1-23.

[3] Angerosa, F., Mostallino, R., Basti, C., Vito, R. (2001) Influence of malaxation temperature and time on the quality of virgin olive oils, Food Chemistry 72, pp. 19-28.

[4] Ranalli, A., Pollastri, L., Contento, S., Lannucci, E., Lucera. L. (2003) Effect of olive paste kneading process time on the overall quality of virgin olive oil. European Journal of Lipid Science and Technology 105, pp. 57-67.

[5] Morales, M.T., Aparicio, R. (1999) Effect of extraction conditions on sensory quality of virgin olive oil, Journal of the American Oil Chemists Society 76, pp. 295-300.

[6] Boskou, D. (1996) Olive Oil: Chemistry and Technology, AOCS Press, Champaign, Illinois.

[7] Petursson, S., Decker, E.A., McClements, D.J. (2004) Stabilization of oil-in-water emulsions by cod protein extracts, Journal of Agricultural and Food Chemistry, 52, pp. 3996-4001. 
[8] Cruz, S., Yousfi, K., Pérez, A.G., Mariscal, C., García, J.M. (2007) Salt improves physical extraction of olive oil, European Food Research and Technology 225, pp. 359-365.

[9] Ranalli, A., Pollastri, L., Contento, S., Lucera, L., Del Re P. (2003) Enhancing the quality in virgin olive oil by use of a new vegetable enzyme extract during processing,

[10] Fernandez, D.G., Espínola, F., Moya, M. (2008) The influence of different technological coadjuvants on the quality and yield of virgin olive oil using response surfaces methodology, Grasas y Aceites 59, pp. 39-44.

[11] Hutchison, P.R., Healy, T.W. (1990) Coagulation and Flocculation-Destabilizing practices? (with particular reference to metal ion coagulants). In: Surface and Colloid Chemistry in Natural Waters and Water Treatment, Ed. Plenum Press, New York, pp. 119-134.

[12] Nemerow, N.L., Dasgupta, A. (1991) Industrial and Hazardous Waste Treatment, Ed. Van Nostrand Reinhold, New York.

[13] Dentel, S.K. (1991) Coagulant control in water treatment, Critical Reviews in Environmental Control 21, pp. 41-135.

[14] Swiderska-Bróz, M. (1991) On the manifold role of lime coagulation, Water Science and Technology 24, pp. 247-253.

[15] Zotter, K., Licskó, I. (1992) Coagulation and Flocculation in alcaline media - the role of $\mathrm{Ca} 2+$ and $\mathrm{Mg} 2+$ ions, Chem. In: Water Wastewater Treat. II, Proceedings of Gothenburg Symposium, fifth ed. Springer, Berlin, pp. 47-64.

[16] Commission of the European Communities. (2011) Commission regulation (EC) No 61/2011 of 24 January 2011 amending regulation (EEC) 2568/91 of 11 July 2001 on the characteristics of olive oil and olive-pomace oil and on the relevant methods of analysis.

[17] Commission of the European Communities. (2003) Commission regulation (EC) 1989/2003 of 6 November 2003 amending regulation (EEC) 2568/91 on the characteristics of olive oil and olive-pomace oil and on the relevant methods of analysis. Official Journal of the European Union L 295, pp. 57-77.

[18] Montgomery, D.C. (1997) Design and Analysis of Experiments, forth ed. John Wiley \& Sons, New York. 